\title{
Giant Filiform Polyposis, A Rare Entity in a Patient of Ulcerative Colitis: A Case Report
}

\author{
Zafar Ali $^{1,2}$, Salma Iltaf ${ }^{1}$ \\ 1. Histopathology, Shifa International Hospital, Islamabad, PAK 2. Pathology, Shifa College of Medicine, Islamabad, \\ PAK \\ Corresponding author: Zafar Ali, zafarali@hotmail.com
}

\section{Abstract}

Filiform polyposis (FP) of the colon is a distinct and uncommon entity that is occasionally encountered in patients with a history or evidence of inflammatory bowel disease. It is morphologically characterized by multiple, slender, worm-like projections consisting of submucosal cores lined with normal mucosa. Here, we report a case of FP in a 43-year-old middle-aged man with a history of inflammatory bowel disease (ulcerative colitis).

\section{Categories: Pathology}

Keywords: filiform polyposis, inflammatory bowel disease, ulcerative colitis

\section{Introduction}

Filiform polyposis (FP) is most frequently secondary to a post-inflammatory reparative process and may occur in $10 \%-20 \%$ of the cases of inflammatory bowel disease in which chronic inflammation of the large bowel mucosa with repeated ulceration and healing may lead to the formation of worm-like polypoid projections [1-3].

The term was first coined by Appleman et al. who used it to describe a syndrome involving the radiological appearance of numerous, long, slender, worm-like, or filiform defects in the colon [4].

FP typically presents as one to hundreds of uniform, slender, arborizing, vermiform projections of the bowel mucosa and submucosa lined by normal or inflamed mucosa. These polyps are thin, straight-shaped, resembling the stalk of polyps without the heads. In rare cases, polyps coalesce and a large tumor mass, which may measure over $15 \mathrm{~mm}$, known as giant filiform polyposis (GFP), is found.

Received 10/28/2019

Review began 11/10/2019 Review ended 11/10/2019 Published 11/11/2019

๑) Copyright 2019

Ali et al. This is an open access article distributed under the terms of the Creative Commons Attribution License CC-BY 3.0., which permits unrestricted use, distribution, and reproduction in any medium, provided the original author and source are credited.

\section{Case Presentation}

The patient presented with per rectum bleeding, no family history of colon polyps, colon cancer, or inflammatory bowel disease (IBD). He received steroid therapy for an unknown period on a clinical basis and remained symptomatic. Later, multiple colonic biopsies were done and revealed chronic active colitis with the possibility of IBD, most likely ulcerative colitis. The patient underwent total colectomy. The specimen showed numerous polyps, more than 100 , up to $2.0 \mathrm{~cm}$ in size (Figure 1). 


\section{Cureus}

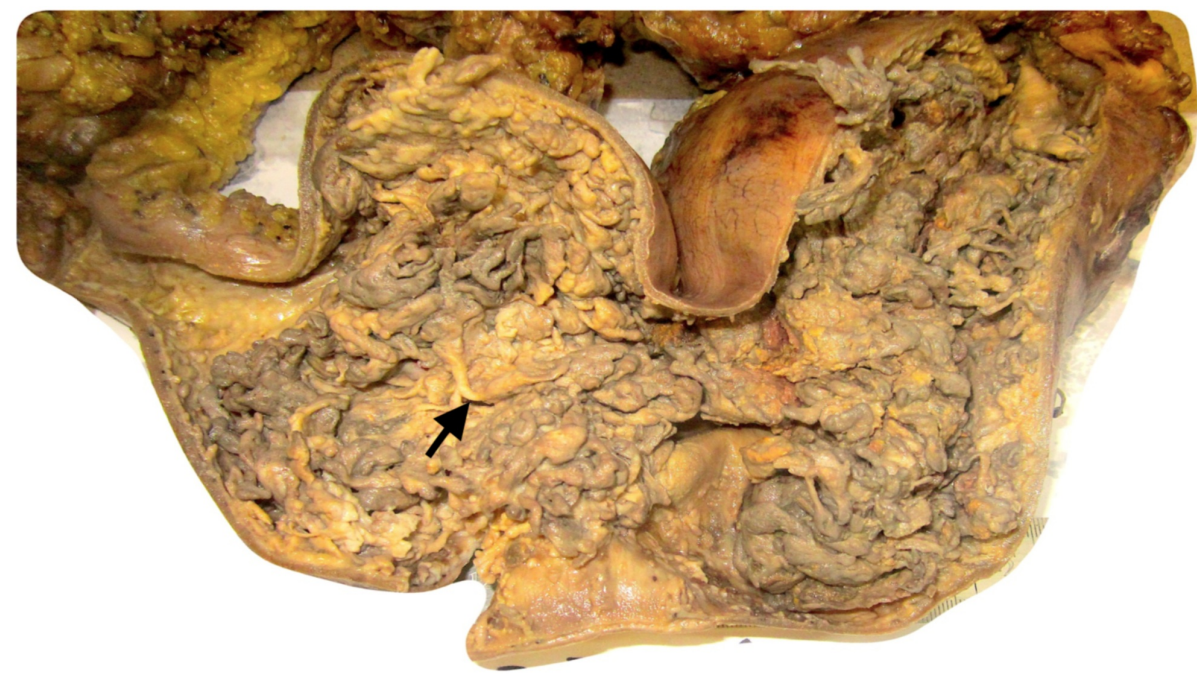

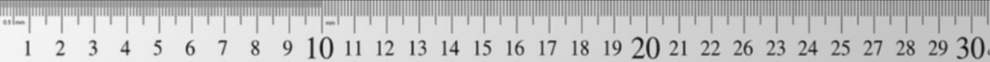

FIGURE 1: Numerous polyps, more than 100 , up to $2.0 \mathrm{~cm}$ in size, involving the entire colon

Histological examination of the sampled polyps showed elongated projections of colonic mucosa showing branched elongated glands and cystic crypts. The central core was composed of submucosal tissue containing vessels, nerves, and lymphoid aggregates (Figures 2-3).

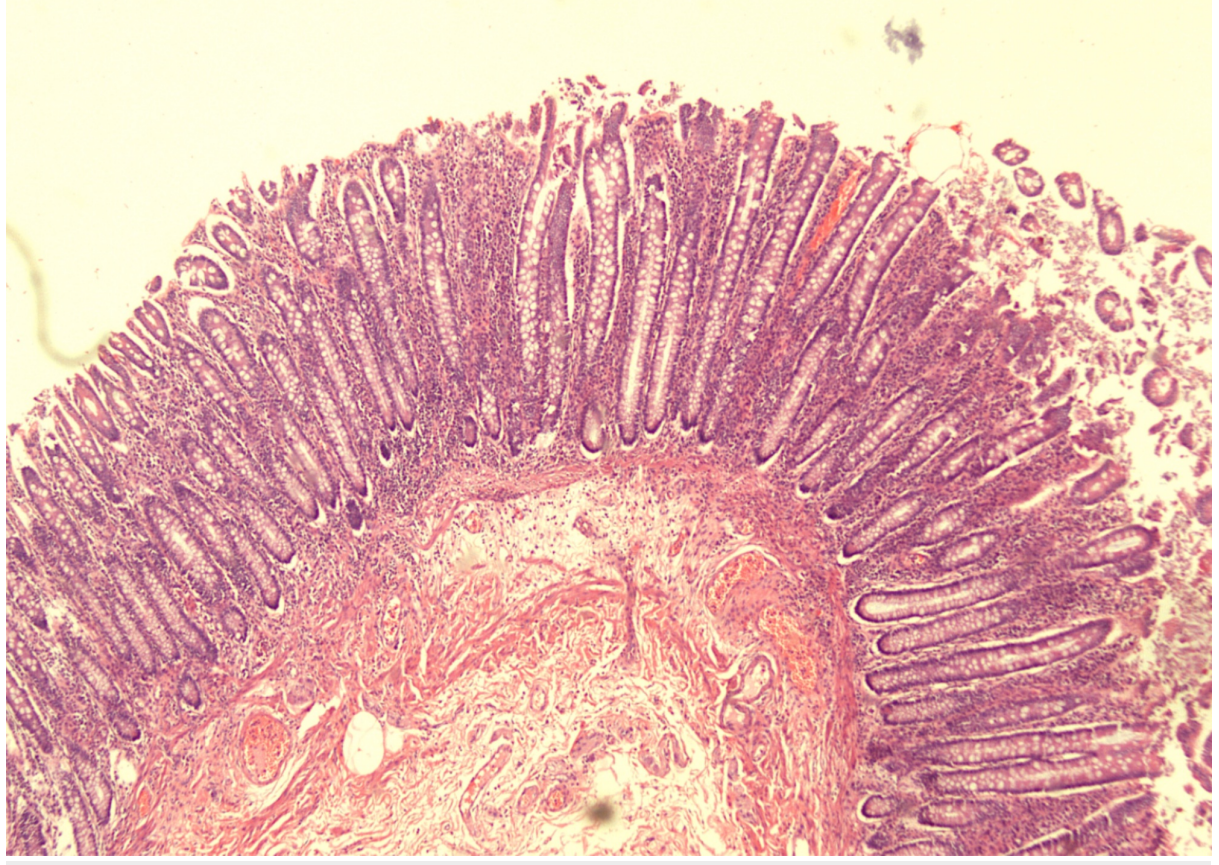

FIGURE 2: Low-power view showing slender, worm-like projections consisting of submucosal cores lined with normal mucosa (x40 magnification) 


\section{Cureus}

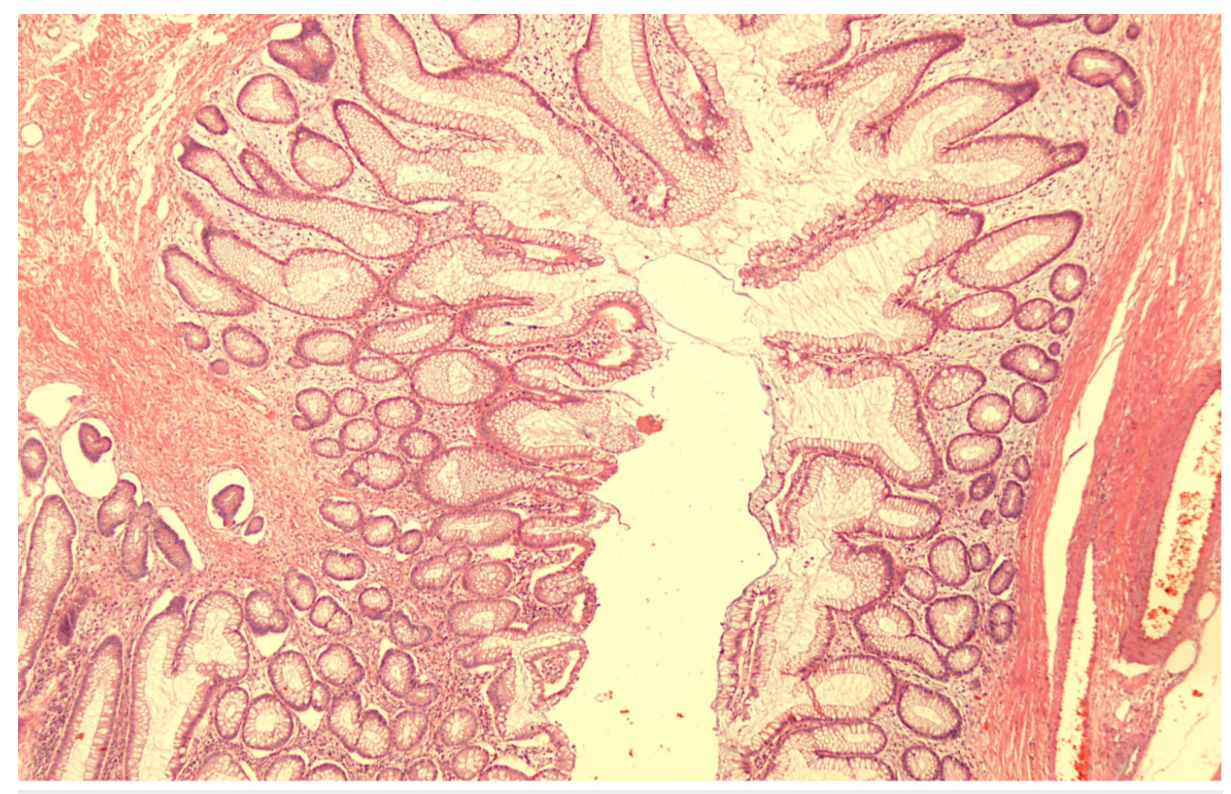

\section{FIGURE 3: Low-power view of sampled polyps with elongated projections of colonic mucosa, showing branched glands and cystic crypts (x40 magnification)}

There were areas of ulceration and abscess formation. The surrounding mucosa shows crypt abscesses, cryptitis, and basal plasmacytosis. There are areas of ulceration and abscess formation. At places, the infiltrate is invading the muscle layer. No dysplasia or malignancy was observed in the mucosa covering the polyps or surrounding them.

\section{Discussion}

We report a case of previously undiscovered polyposis in the entire colon, with a definite history of IBD, i.e ulcerative colitis. This report is intended to characterize the clinical and pathologic features of filiform polyposis. Filiform polyposis (FP) is most frequently secondary to a post-inflammatory reparative process of the large bowel mucosa [5]. FP is rare in the pediatric population with few cases reported [6].

FP typically presents as one to hundreds of uniform, slender, arborizing, vermiform projections of the bowel mucosa and submucosa lined by normal or inflamed mucosa. These polyps are thin, straight-shaped, resembling the stalk of polyps without the heads. When these polyps form tumor-like masses, as in our case, they are called giant filiform polyposis (GFP). Grossly, these giant polyps may be mistaken for malignancy. Microscopically, these polypoidal structures are lined by bland-appearing epithelium with no evidence of dysplasia. The adjacent mucosa will show changes of chronic active inflammation as a sequela of IBD. The gross identification and knowledge of this entity is essential for making a correct diagnosis.

Although the presence of dysplasia or malignant transformation has never been reported in FP, in some cases, the polyps are difficult to distinguish from villous adenomas, and biopsies are needed to make the diagnosis [7]. Our case did not show any evidence of dysplasia or invasive malignancy. Partial colectomies should be reserved for complicated cases of symptomatic inflammatory polyps or when malignancy cannot be excluded [8]. For example, if it is thought that FP has developed in association with active IBD, preemptive surgical resection would seem reasonable as in our case, particularly given the increased risk of colon cancer with ulcerative colitis and Crohn's disease [9-11]. However, in asymptomatic patients without a history who are found to have FP, observation is the best option. When patients with inflammatory polyposis require surgical management, it is important to evaluate the margins of resection because inflammatory polyposis can recur in the presence of acute inflammation or residual disease at the resected margins.

\section{Conclusions}

Giant filiform polyposis can grossly mimic adenomatous polyps or colorectal carcinoma. It should be considered in the differential diagnosis of patients presenting with polyposis in IBD. A thorough sampling of the specimen is required to exclude dysplasia or invasive malignancy. A periodic, close follow-up is suggested.

\section{Additional Information}




\section{Disclosures}

Human subjects: Consent was obtained by all participants in this study. Conflicts of interest: In compliance with the ICMJE uniform disclosure form, all authors declare the following: Payment/services info: All authors have declared that no financial support was received from any organization for the submitted work. Financial relationships: All authors have declared that they have no financial relationships at present or within the previous three years with any organizations that might have an interest in the submitted work. Other relationships: All authors have declared that there are no other relationships or activities that could appear to have influenced the submitted work.

\section{References}

1. Brozna JP, Fisher RL, Barwick KW: Filiform polyposis: an unusual complication of inflammatory bowel disease. J Clin Gastroenterol. 1985, 7:451-458. 10.1097/00004836-198510000-00019

2. Orlowska J, Jarosz D, Bielecki K, Wejman J: Diffuse filiform polyposis of the colon in Crohn's disease . APMIS. 1996, 104:94-98. 10.1111/j.1699-0463.1996.tb00692.x

3. Oakley III GJ, Schraut WH, Peel R, Krasinskas A: Diffuse filiform polyposis with unique histology mimicking familial adenomatous polyposis in a patient without inflammatory bowel disease. Arch Pathol Lab Med. 2007, 131:1821-1824.

4. Sheikholeslami M-R, Schaefer RF, Mukunyadzi P: Diffuse giant inflammatory polyposis: a challenging clinicopathologic diagnosis. Arch Pathol Lab Med. 2004, 128:1286-1288.

5. Thilakarathne B, Rathnayake R, Kappetiyagama C, Vithanage A, Walisingha D, Sugathadasa W: Giant filiform polyposis in a patient with inflammatory bowel disease presenting with intestinal obstruction. J Diag Pathol. 2017, 25:22-25. 10.4038/jdp.v12i2.7742

6. Urgancı N, Kalyoncu D, Tanık C: Filiform polyposis in ulcerative colitis: a rare pediatric case . Balkan Med J. 2018, 35:400-401. 10.4274/balkanmedj.2018.0136

7. Bauknecht KJ, Grosse G, Kleinert J, Lachmann A, Niedobitek F: Filiform polyposis of the colon in chronic inflammatory bowel disease*(so-called giant inflammatory polyps) [Article in German]. Z Gastroenterol. 2000, 38:845-859. 10.1055/s-2000-9994

8. Pidala M, Slezak F, Hlivko T: Delayed presentation of an inflammatory polyp following colonic ischemia . Am Surg. 1993, 59:315-318.

9. Ponte R, Mastracci L, Di Domenico S, Ferretti C, De Cian F, Fiocca R, Grillo F: Giant filiform polyposis not associated with inflammatory bowel disease: a case report. Visc Med. 2015, 31:58-60. 10.1159/000370342

10. Kim H-S, Lee KY, Kim YW: Filiform polyposis associated with sigmoid diverticulitis in a patient without inflammatory bowel disease. J Crohns Colitis. 2010, 4:671-673. 10.1016/j.crohns.2010.05.009

11. Lim YJ, Choi JH, Yang CH: What is the clinical relevance of filiform polyposis? . Gut Liver. 2012, 6:524-526. 10.5009/gnl.2012.6.4.524 